\title{
Com prendre consciència de la contaminació sonora. Realització de treballs de recerca sobre el tema
}

\author{
Luisa Herreras Blanco, \\ IES Guillem de Berguedà, Berga \\ lherrer1@xtec.cat
}

A partir de les activitats proposades amb motiu de l'Any Internacional de la Física, durant dos cursos consecutius hem realitzat treballs de recerca relacionats amb la contaminació acústica. El primer amb l'objectiu de determinar el nivell acústic de Berga i el segon per estudiar els sorolls als que està sotmès un jove de secundària d'aquesta ciutat en les seves activitats quotidianes.

\section{Introducció}

Cada dia són més freqüents les notícies sobre el soroll a les ciutats, tema que preocupa cada vegada més a la nostra societat. És per això que no podem deixar de treballar-lo a les nostres aules, quan es tracta de formar ciutadans responsables, sensibles i crítics amb el seu comportament i amb la gestió de l'entorn.

Vivim en una zona rural on el jovent utilitza molt sovint la moto per desplaçar-se i és habitual que la portin trucada, sense tenir en compte el possible malestar que pot generar en els seus veïns.

Des de l'any 2000, inici de la nostra participació en el Projecte Escoles Verdes, hem proposat com un dels objectius del centre l'elaboració de treballs de recerca de temàtica mediambiental.

Durant l'Any Internacional de la Física, l'Associació de Professores i Professors de Física i Química de Catalunya (APFQC) va proposar una sèrie d'activitats amb motiu de la seva celebració.

A més, l'arribada als centres de la dotació del material Multilog ens va permetre introduir-nos en la seva utilització, prenent dades de forma automàtica per poder dedicar-nos a una millor realització dels nostres treballs pràctics.

Aquestes circumstàncies van ser la causa de l'elaboració, durant els cursos 2005-2006 i 20062007 , de dos treballs relacionats amb la contaminació acústica.

Un grup d'alumnes va decidir treballar en les activitats proposades per l'APFQC i, a continuació, cada alumne es va especialitzar en una temàtica. L'estudi del benestar a les aules va resultar molt suggerent, però donades les dates en que érem, vàrem haver de derivar-ho a un altre tema que ens resultava també molt interessant: són els nostres carrers tan sorollosos com de vegades ens sembla? Potser és una percepció subjectiva? Depassen els límits legals? Quina és la normativa vigent?

Va ser d'aquesta manera com ens vàrem engrescar en l'estudi del nivell sonor a Berga durant l'estiu de l'any 2005; així va néixer el treball de recerca "Plens de soroll", amb l'objectiu de realitzar el mapa sònic de la ciutat.

El segon treball ha estat realitzat durant el present curs 2006-07 i la pregunta que ens plantejàrem fou quins eren els nivells sonors a què està sotmès un jove de l'edat dels alumnes de l'institut, al llarg d'una jornada. Per fer-ho, aquest alumne va enregistrar la intensitat sonora de totes les seves activitats, estudiant els nivells sonors de cadascuna d'elles.

Ambdues recerques van concloure amb possibles mesures encaminades a reduir el soroll, tant des de l'administració com a nivell personal.

\section{Contaminació acústica}

Encara que lentament, la nostra societat està assumint la preocupació pel medi ambient, i es promou la lluita contra diversos tipus de contaminació, com la dels rius, la de l'atmosfera, etc. En aquests darrers anys, a nivell estatal i europeu també s'està començant a prevenir la contaminació acústica d'una manera legal i administrativa, ja que és un dels factors de deteriorament de la qualitat de vida.

Pràcticament tot el que fem va acompanyat d'alguna classe de so que, molt sovint, pot arribar a 
suposar una incomoditat, fins i tot greu, per a tot aquell que es veu obligat a sentir-lo; en aquest cas, deixem de parlar de so per anomenar-lo soroll.

\section{Soroll i salut}

El soroll és un contaminant susceptible d'afectar la salut de les persones i la seva qualitat de vida per la seva incidència en la comunicació, el comportament, l'estat d'ànim i l'estat nerviós.

La molèstia per soroll porta implícit un fort component subjectiu. Un mateix so pot ser considerat agradable o molest segons les seves característiques, les del moment en què es produeix i la sensibilitat del receptor.

Quan comencem a tenir els primers símptomes de mal funcionament al nostre sistema auditiu, és degut a que ja fa temps que patim trastorns en el nostre organisme, encara que l'oïda no els manifesta fins que n'hi ha un seguit d'acumulats (disminució temporal o permanent de la capacitat auditiva, manifestacions de sensacions de molèstia, nerviosisme, irritabilitat, interferències en la son) que produeixen cansament, disminució del rendiment, alteracions del metabolisme, del sistema nerviós central, del sistema neurovegetatiu, etc. Això, entre d'altres coses, fa que la contaminació acústica derivi en un greu problema per a la salut.

\section{Fonts de soroll}

Hi ha una sèrie de fonts sonores que provoquen grans quantitats de soroll cada dia, a una intensitat molt elevada. Les principals són la construcció, les activitats industrials i les activitats urbanes comunitàries (mercats i locals comercials, locals d'espectacles o discoteques, repartiment urbà de mercaderies, recollida d'escombraries, col-legis, ...).

Els sorolls produïts per aquestes últimes activitats es caracteritzen per la seva intermitència i la fluctuació dels nivells sonors, que poden sobrepassar els $90 \mathrm{~dB}$.

\section{La legislació a Catalunya i a Berga}

Com que les competències en medi ambient són potestat de la Generalitat, és aquesta qui ha de regular i legislar el soroll a tot el territori català. No obstant això, cada ajuntament elabora una ordenança municipal per tal d'adequar-la a la llei catalana.

Un dels elements més destacats de la llei autonòmica és la zonificació acústica que classifica el territori en funció dels nivells de contaminació per- mesos. A part de les diferents zones, també especifica el nivell acústic màxim durant l'horari diürn (8h - 22h), i nocturn (22h - 8h). Però, a més a més, fa una distinció entre els valors màxims permesos dins dels habitatges o a l'exterior.

Berga disposa d'una ordenança per a millorar la qualitat sonora ambiental que data de l'any 1994. Ha estat revisada i modificada lleugerament per adequar-la a la llei 16/2002 aprovada per la Generalitat.

\section{Sonòmetre}

El sonòmetre encarregat de captar i enregistrar la intensitat sonora que vàrem utilitzar es caracteritza per tenir un nivell de precisió de $+/-2 \mathrm{~dB}$, una resolució de 0,1 dB, un rang de mesura de 20 - 120 $\mathrm{dB}$ aproximadament, l'opció de memoritzar el màxim i mínim de cada mesura i el nivell mitjà de tot el període enregistrat.

L'aparell que vàrem fer servir, recomanat pel CDECT (Centre de Documentació i Experimentació en Ciències i Tecnologia), va ser el de la marca CENTER, de la sèrie 320. Disposa d'una memòria interna per a emmagatzemar uns 30.000 valors $i$ una connexió per a PC.

Les mesures es portaren a terme amb el sonòmetre en posició de rang automàtic, velocitat de resposta ràpida i nivell $A$ de recepció.

Els valors màxim i mínim ens indiquen les puntes sonores, que són les que normalment molesten més, encara que per realitzar cada estudi ens fixàrem en el valor mitjà de cada enregistrament.

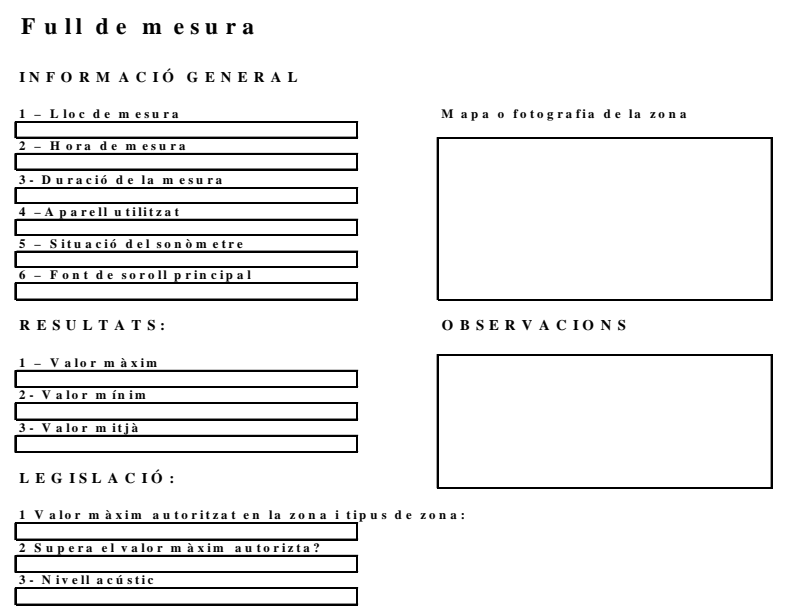

Fitxa 1. Recollida de dades

Al primer treball els punts d'enregistrament triats estaven repartits per tota la ciutat a fi d'obtenir una informació el més variada possible (segons la font 
sonora, el tipus de zona, o la concurrència del carrer). Ens fixàrem en les diferents catalogacions de les zones, segons el seu nivell de protecció acústica (alta, mitjana o baixa). Les mesures també es van dividir tenint en compte la franja horària (horari diürn o nocturn).

Per tal de sistematitzar la recollida de dades dels 20 indrets estudiats es va elaborar una fitxa (fitxa 1). El resum dels resultats obtinguts es mostren a la taula 1.

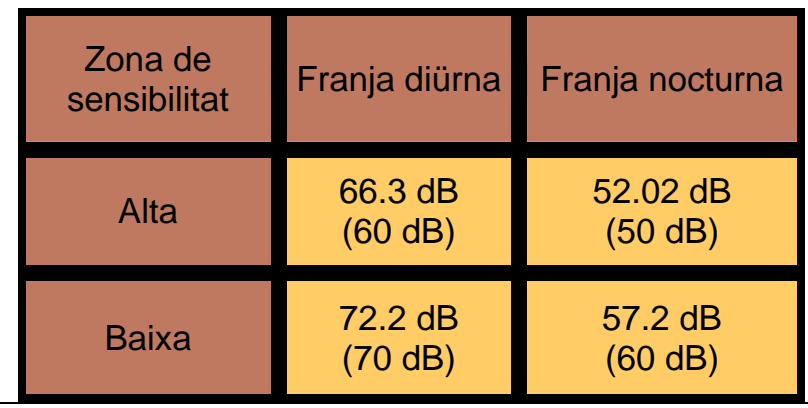

Taula 1. Resum dels enregistraments d'intensitat sonora obtinguts a la ciutat de Berga. Entre parèntesis es detallen els límits permesos legalment segons l'ordenança de Berga.

La majoria dels valors mitjans enregistrats, tant en horari diürn com en el nocturn, obtingueren valors superiors al màxim autoritzat per la llei, arribant a puntes de fins a $90 \mathrm{~dB}$.

Es va comprovar que la diferència dels nivells enregistrats segons la zona de la ciutat i l'hora d'enregistrament venia donada principalment en funció de la densitat del tràfic rodat.

A partir de les 12 de la nit, les dades estaven per sota del màxim legal permès.

\section{Mapa sònic de Berga}

Amb els valors obtinguts als diferents punts de mesura es va elaborar un mapa sònic de Berga (figura 1), pintant els carrers segons el nivell acústic obtingut. Aquest sistema s'utilitzà per representar d'una forma àgil i clara els punts més contaminats $i$, en contraposició, els indrets més silenciosos. Per fer-ho s'utilitzà una escala amb els següents intervals:

- Amb color verd els valors inferiors al màxim establert per llei

- Amb taronja els que superen la llei entre 0.1 i 5 $\mathrm{dB}$

- I amb vermell els que superen la llei en més de $5 \mathrm{~dB}$.

De les dades obtingudes, vàrem concloure que Berga pateix contaminació acústica, tenint com a principal font de soroll el trànsit rodat, i amb valors mitjans aproximats d'uns $5 \mathrm{~dB}$ per sobre del que permet la llei, però amb puntes que poden arribar a més $30 \mathrm{~dB}$.

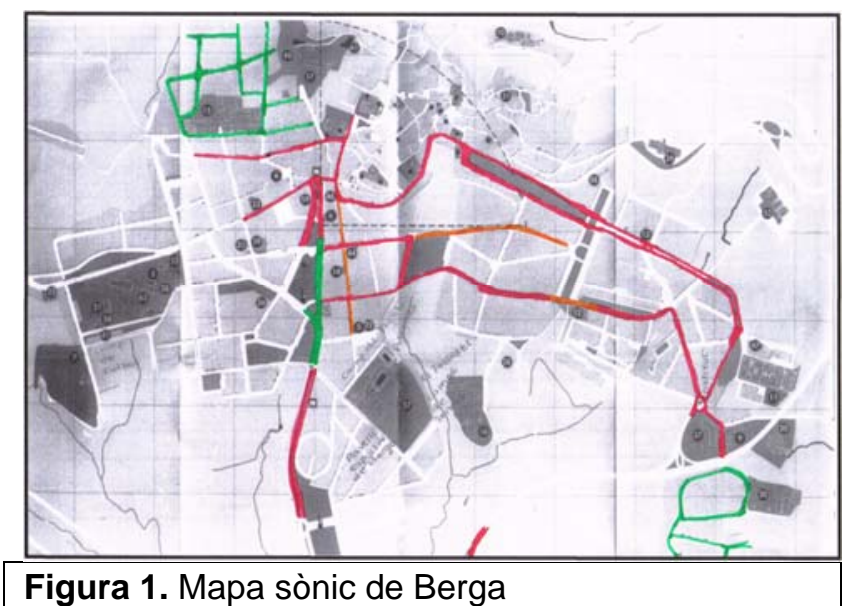

Es va corroborar la importància dels passos elevats de vianants en la disminució de la velocitat $i$, com a conseqüència, la menor intensitat sonora enregistrada al pas dels vehicles per aquests indrets.

\section{Els joves i el soroll}

La contaminació acústica és un problema que afecta la societat en general, però hi ha un sector que és especialment vulnerable: el jovent, ja que els entorns en què es mou i les activitats que du a terme, comporten sovint alts nivells sonors. Això s'agreuja quan hi afegim que els mateixos joves no estan ben informats d'aquest fenomen ni de les conseqüències que se'n poden derivar.

Per aquest motiu vàrem voler continuar la nostra recerca, investigant la mesura de la contaminació acústica en la vida quotidiana d'un jove i la seva percepció dels nivells sonors a què està exposat.

Les situacions més rellevants que es van enregistrar en aquest segon treball van ser, entre d'altres, les següents:

- Aula de l'institut durant les classes del matí (figura 2)

- Sortida de l'institut (figura 3)

- Bar durant un partit de futbol (figura 4)

- Dissabte a un bar musical (figura 5)

- Discoteca (figura 6)

En tots els casos, l'alumne va anar recollint al seu quadern de camp les característiques sonores de cada interval de temps, així com els instants en que havia alguna diferència remarcable. 
Per poder analitzar i interpretar les dades obtingudes es van assenyalar als gràfics certs punts ( $A$, $B, C, D, \ldots)$ quan els valors eren diferents a la mitjana enregistrada, comentant per trams les circumstàncies més significatives que varen produir els resultats.

Un resum de les dades obtingudes en aquests enregistraments és el que es recull a la taula 2. D'ella podem inferir que qualsevol activitat realitzada pel jovent comporta uns nivells sonors molt elevats, superant els $50 \mathrm{~dB}$ que va fixar l'Organització Mundial de la Salut (OMS) com a límit superior d'intensitat sonora desitjable.

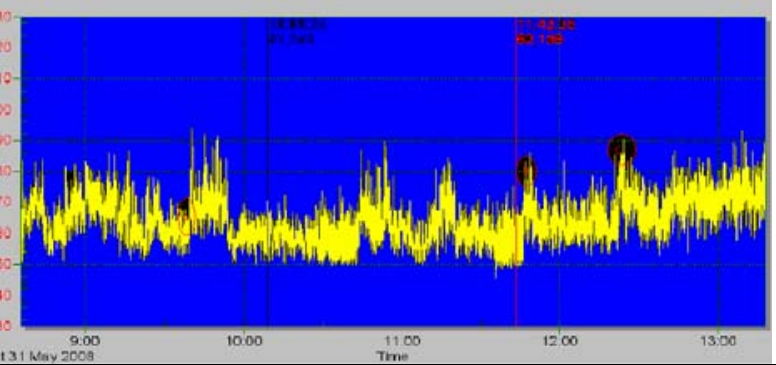

Figura 2. Enregistrament de la intensitat sonora a l'interior d'una classe a l'institut.

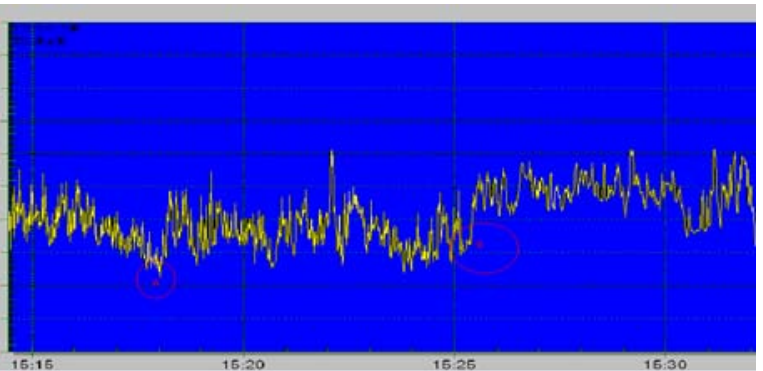

Figura 3. Enregistrament de la intensitat sonora a la sortida de l'institut.

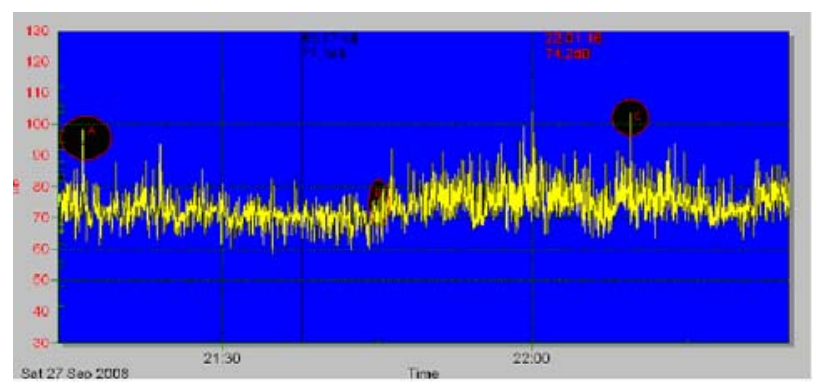

Figura 4. Enregistrament de la intensitat sonora a l'interior d'un bar durant un partit de futbol.

En el primer enregistrament (fig. 2) es va poder observar la diferència entre el nivell sonor de l'aula segons el professor que hi donava classe, el moment de la classe (sempre amb més soroll cap al final, degut al cansament), el tipus d'activitat, etc. També es podien detectar els canvis de classe amb un augment del soroll.

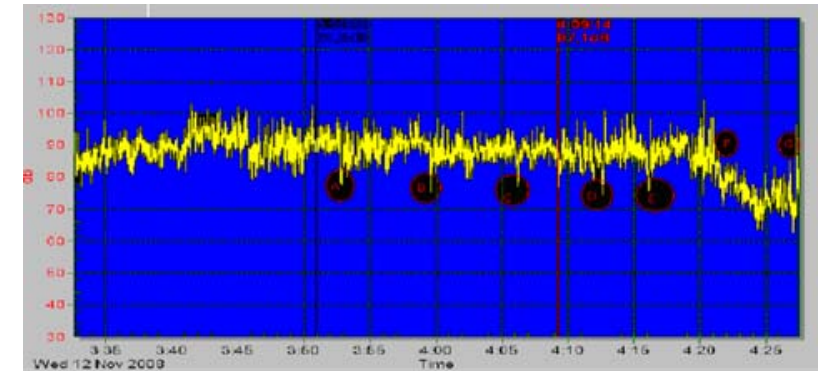

Figura 5. Enregistrament de la intensitat sonora a l'interior d'un bar musical un dissabte a la nit.

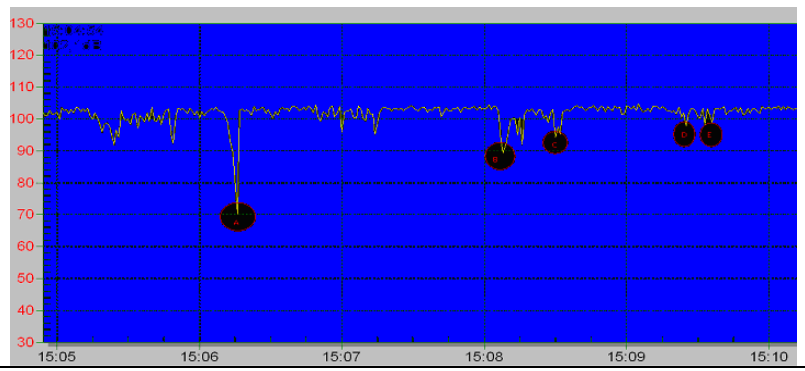

Figura 6. Enregistrament de la intensitat sonora a l'interior d'una discoteca.

\begin{tabular}{|l|c|c|c|c|c|}
\hline $\begin{array}{l}\text { Localit- } \\
\text { zació }\end{array}$ & $\begin{array}{c}\text { Aula de } \\
\text { l'institut } \\
\text { durant les } \\
\text { classes }\end{array}$ & $\begin{array}{c}\text { Exterior de } \\
\text { l'institut }\end{array}$ & $\begin{array}{c}\text { Bar } \\
\text { durant un } \\
\text { partit de } \\
\text { futbol }\end{array}$ & $\begin{array}{c}\text { Bar musical } \\
\text { nocturn }\end{array}$ & Discoteca \\
\hline $\begin{array}{l}\text { Durada de } \\
\text { l'expo- } \\
\text { sició }\end{array}$ & $\begin{array}{c}\text { De } 8: 30 \mathrm{a} \\
13: 30\end{array}$ & $\begin{array}{c}\text { De } 14: 00 \mathrm{a} \\
14: 15\end{array}$ & $\begin{array}{c}2 \text { hores i } \\
\text { mitja aprox. }\end{array}$ & $\begin{array}{c}\text { De les 3:30 } \\
\text { a les 4:30 }\end{array}$ & $\begin{array}{c}\text { De les 3:30 } \\
\text { a les 3:35 }\end{array}$ \\
\hline $\begin{array}{l}\text { Intensitat } \\
\text { màxima }\end{array}$ & $96,8 \mathrm{~dB}$ & $91,2 \mathrm{~dB}$ & $104,0 \mathrm{~dB}$ & $104.1 \mathrm{~dB}$ & $104.7 \mathrm{~dB}$ \\
\hline $\begin{array}{l}\text { Intensitat } \\
\text { mitjana }\end{array}$ & $72,1 \mathrm{~dB}$ & $70,9 \mathrm{~dB}$ & $72,1 \mathrm{~dB}$ & $87.2 \mathrm{~dB}$ & $101.7 \mathrm{~dB}$ \\
\hline
\end{tabular}

Taula 2. Quadre resum dels valors enregistrats amb el sonòmetre en els indrets més freqüentats pels joves

Al segon enregistrament (fig. 3), es van posar en evidència els nivells sonors que emet un determinat tipus de motocicletes, generalment molt elevats. Al nostre centre n'hi ha una trentena, algunes amb trucatge, amb el conseqüent augment del nivell sonor. A la sortida de l'institut és el moment en què es detecta major soroll per la coincidència de totes elles.

Els següents gràfics van corroborar que la intensitat sonora en certs espais d'oci, molt freqüentats pel jovent, suposen una gran perillositat per la seva salut. A la discoteca (fig. 6) es manté de manera continuada una mitjana de $102 \mathrm{~dB}$.

Tots aquests resultats, més la realització d'una enquesta, posaren de manifest el fet que el jovent no coneix les conseqüències de trobar-se sotmesos a nivells tan elevats de soroll de manera continuada. 
Així les persones que van realitzar els treballs hi afegiren mesures a fi de tractar de minvar l'exposició als sorolls en la seva vida i també varen reivindicar una educació amb més coneixement en aquest tema per tal de sensibilitzar la societat.

\section{Valoració dels resultats obtinguts, perspectives d'evolució i continuació}

Durant aquets dos cursos, les recerques realitzades han permès als alumnes adonar-se dels nivells legals sonors que existeixen i de com se superen en qualsevol lloc i activitat de la seva vida quotidiana.

També han estudiat les seves conseqüències sobre la salut, amb la possible adquisició d'importants patologies.

És per això que ens hem plantejat la necessitat de generalitzar aquest estudi amb els alumnes de secundària obligatòria, a 4t d'ESO, dins de la unitat 12: "Ones. Llum, so i radiacions", perquè tots prenguem consciència de que superem els valors màxims sonors regulats actualment, i de la seva repercussió en la salut a l'hora de prendre decisions. Contribuir, en definitiva, a fer que siguin ciutadans responsables.

Des d'una visió CTS, amb la utilització de les TIC i com a activitat de la corresponent unitat, podran realitzar un treball pràctic que ens sembla de gran importància a nivell social, aplicant la metodologia científica.

\section{Bibliografia}

Aymerich Torner, F.(2006). Plens de soroll. Treball de recerca.

Pons Rabat, G.(2007). Els joves i el soroll. Treball de recerca. 